\title{
Knowledge and Attitude Regarding Infection Control Among Undergraduate Dental Students At B.P.Koirala Institute of Health Sciences
}

Pujan Acharya ( $\sim$ poojan_drn@yahoo.com )

Institution: B. P. Koirala Institute of Health Sciences

Ratna Baral

Institution: B. P. Koirala Institute of Health Sciences

Sajeev Shrestha

Institution: B. P. Koirala Institute of Health Sciences

Dharanidhar Baral

Institution: B. P. Koirala Institute of Health Sciences

\section{Research Article}

Keywords: Attitude, Infection control, Knowledge, Undergraduate dental students

Posted Date: July 7th, 2021

DOl: https://doi.org/10.21203/rs.3.rs-671272/v1

License: (c) (i) This work is licensed under a Creative Commons Attribution 4.0 International License.

Read Full License 


\section{Abstract \\ Background}

In academic institutes, dental students are not only involved in academic activities, but also in the management of patients' care. This calls for inculcation of adequate knowledge and positive attitude among them so that a good clinical practice is implemented in the dental setting, thereby creating a safe working environment for students as well as patients. Thus, the study was conducted to assess knowledge and attitude regarding infection control among undergraduate dental students of B.P.Koirala Institute of Health Sciences, Dharan, Nepal.

\section{Methods and materials:}

An online descriptive cross-sectional study was conducted at BPKIHS from February till March 2021. Undergraduate students from third year, fourth year and internship were included in the study. A selfadministered questionnaire comprised of demographic, knowledge and attitude regarding infection control was used to collect the data via a Google form. Descriptive and inferential statistics was used to analyze the data. The p value $<0.05$ was considered statistically significant at $95 \%$ confidence interval.

\section{Result}

A total of 136 undergraduate dental students participated out of which $65.0 \%$ were females and $35.0 \%$ were males. Out of the total participants, $78.7 \%$ were found to have adequate knowledge while $74.3 \%$ participants showed 'positive' attitude. Mean age of the participants with adequate knowledge was significantly higher than participants with inadequate knowledge $(p=0.047)$. The difference in knowledge among participants was statistically significant $(p=0.001)$ in academic years. The majority $(90.4 \%)$ of interns showed adequate knowledge followed by fourth year $(83.7 \%)$ and third year $(58.7 \%)$ students. The difference in attitude, was also statistically significant $(p=0.011)$ in academic years, but it was mostly $(90.4 \%)$ of positive attitude in fourth year participants followed by third year (68.3\%) and Interns (65.4\%).

\section{Conclusion}

The present study reports adequate knowledge and positive attitude regarding infection control among undergraduate dental students in BPKIHS. Further studies are encouraged to be conducted among students from different academic institutes all over the country to ascertain their level of attitude and knowledge regarding infection control in dental care services.

\section{Introduction:}


Health care service is associated with the potential risk of infection transmission. ${ }^{1}$ Dental health care service being a part of it, is no exception to this risk. Hence, dental clinic (set up) is strongly considered as an environment where such transmissions occur easily. ${ }^{2}$ Majority of routinely performed dental procedures have the potential to create contaminated aerosols and splatter which puts the dental health care providers (DHPs) at risk of exposure to air-borne as well as blood-borne pathogens. Taking this fact into account, centers for disease control and prevention (CDC) first published the infection control recommendations for dentistry in 1986, and last updated in 2003. These guidelines include precautions which aimed to ensure a safe working environment and prevent transmission of occupational and nosocomial infections among DHPs and their patients. ${ }^{3}$ Therefore, it is the responsibility of every dental institute to provide appropriate measures for the establishment of safer working conditions. ${ }^{4}$

In academic institutes, dental students come under the highly afflicted category of DHPs in terms of contracting infectious diseases. This could be attributed to the fact that, they are steadily/directly involved in the management of patients as part of their curricular practical training. Additionally, the fact that, the persons seeking dental care also pose high risk as they could be in prodromal phase or could be the carriers of certain infectious diseases, about which they themselves might be unaware. ${ }^{5}$ Furthermore, the naivety of undergraduate dental students themselves could also be one of the factors responsible for making them more susceptible to such contractions because, even experienced professionals have been reported of not taking the risk of infection transmission seriously and hence exhibiting negative attitude towards infection control. ${ }^{1}$ Several studies have been conducted across different countries to assess knowledge, attitude and practice related to infection control among undergraduate dental students with varying results. A systematic review conducted in Iran demonstrated an inappropriate level of knowledge, attitude and practice among Iranian dentists and dental students regarding infection control. ${ }^{6}$ Similar findings were demonstrated in a study conducted in India among undergraduate dental students. ${ }^{7}$ The level of knowledge regarding infection control in Nepal has been shown to be no different than these countries. A study was conducted among dental students and interns in one of the dental colleges in Nepal, to assess their awareness related to infection control. The study revealed inadequate knowledge and compliance yet a positive attitude towards infection control protocols. ${ }^{4}$ However, another study concluded that dental health care professionals had satisfactory knowledge yet poor practice related to infection control during impression making. ${ }^{8}$

Such assessment helps to derive information pertaining to existing lacunae regarding knowledge and attitude amongst them. As a result, focused supervision could be implemented during their clinical training to motivate strict adherence to the guidelines. Therefore, the present study was conducted to assess the level of academic knowledge acquired in relation to infection control and subsequently, their attitude towards infection control guidelines in their clinical practice.

\section{Materials And Methods:}

\section{Study design and setting:}


An online descriptive cross-sectional study was conducted among the undergraduate dental students at college of dental surgery, BPKIHS, Dharan, Nepal. A link was sent to the participants including a brief introduction on the background, objective of the study, voluntary nature of participation, declarations of confidentiality and anonymity followed by questions on demographic characteristics, knowledge, and attitude regarding infection control in dental setting.

\section{Study participants:}

Inclusion Criteria: a) The undergraduate dental students of third, fourth year and internship and b) Students who agreed to participate were included in the study.

Exclusion Criteria: a) First- and second-year students were excluded because students are not exposed to clinical practice until they reach third year and the final years students not existent due to fourth year examination delay for COVID - 19 pandemic.

\section{Sampling method:}

The sample size adequacy was estimated by considering 95\% confidence interval $(\mathrm{Cl})$ and $80 \%$ power. According to study carried by Alharbi et al good attitude was found to be $67.2 \% .{ }^{9}$ So, by using one proportion formula sample size calculation was become:

$\mathrm{n}=\mathrm{z}^{2} \mathrm{pq} / \mathrm{d}^{2}$ where, $\mathrm{z}=1.96$ at $95 \% \mathrm{Cl}$

$$
\begin{aligned}
& p=67.2 \\
& q=100-67.2 \\
& d=20 \% \text { of } 67.2=13.44 \text { at } 80 \% \text { power }
\end{aligned}
$$

Now, placing the value in equation, it becomes:

$\mathrm{n}=(1.96)^{2} \times 67.2 \times 32.8 /(13.44)^{2}$

$=46.87 ه 47$

After, adding $10 \%$ to calculated sample size for reduction of various biases, actual sample size was determined to be 52 . However, all the students studying in third year, fourth year and internship were included in the study. Hence, total target population size was 160 students.

\section{Data collection procedure and tools:}

The data collection tool was a self-administered questionnaire which consisted of 26 closed ended questions. It was constructed using items designed to reflect CDC guidelines towards infection control in dental health care setting along with further appropriate questions relevant to routine clinical practice of dental students or professionals in the dental setting. The prepared questionnaire was presented at the 
concerned departments for content validity and accordingly suggestions were incorporated. The finalized questionnaire was thereupon subjected to pilot study among $10 \%$ of sample size to assess its reliability, for which it was converted into a web-based format (Google Forms) and sent through social networking websites. The data from participants $(n=16)$ of the pilot study were excluded from the final analysis.

The results did not show acceptable internal consistency of the tool. Therefore, it was re-constructed which now comprised of 21 questions after item deletion and reframing. out of which 13 questions were based upon knowledge and 8 on attitude related to infection control in dental setting. A revised and finalized version was then re-piloted among the same study sample which, upon reliability analysis, showed that Cronbach's coefficient alpha for knowledge and attitude was 0.724 and 0.714 , respectively.

For the knowledge questions, incorrect or uncertain responses (I do not know, and I do not remember) were given score 0 while, score 1 was assigned for correct answer. For attitude questions, responses were graded on a 5-point Likert scale, an agreement scale ranging from strongly agree, agree, uncertain, disagree, and strongly disagree which were scored as 4,3,2,1 and 0 respectively. The expected maximum total knowledge score for knowledge and attitude were 13 and 32 respectively. The scores for all the questions were summed up and the mean score was calculated, which then was expressed as percentage and further interpreted according to modified Bloom's cut off point. ${ }^{10}$ Level of knowledge was considered "adequate" if the score was above $80 \%$, and attitude to be "positive" if above $90 \%$.

\section{Data Analysis:}

The data collected via online questionnaire were stored in MS excel 2007 and then converted into Statistical Package for Social Sciences (SPSS) 11.5 version for statistical analysis. Descriptive statistics were presented in percentage, mean and SD along with graphical and tabular form, whereas inferential statistics, independent t-test and chi-square test was applied to find out the significant difference between selected variables with attitude and knowledge regarding infection control. The $p$ value $<0.05$ was considered statistically significant at $95 \%$ confidence interval.

\section{Results:}

\section{Demographic Characteristics:}

The expected sample size was 144 after eliminating $10 \%$ of the study sample $(n=16)$ included in the pilot test. So, out of 144 existing students only 136 (94.4\%) responded to the questionnaire. Among them, $89(65.0 \%)$ were females and $47(35.0 \%)$ were males. The mean age of the participants was 23.96 with SD 1.03 years. The academic year distribution of third, fourth and intern were 41 (30.2\%), 43 (31.6\%) and $52(38.2 \%)$ students respectively in the study.

\section{Knowledge And Attitude Of Participants:}


The distribution of responses on knowledge and attitude questionnaires has been shown in Tables 1 and 2 respectively. Of the total participants, 107 (78.70\%) were found to have 'adequate' knowledge while 101 (74.30\%) participants were found to have 'positive' attitude.

Table 1

Responses of participants on knowledge questionnaire

\begin{tabular}{|llll|}
\hline \multirow{2}{*}{ Question No } & \multicolumn{3}{l|}{ Response [n, (\%)] } \\
\cline { 2 - 4 } & Yes & I don't know & No \\
\hline K1 & $136(100 \%)$ & 0 & 0 \\
\hline K2 & $111(81.6 \%)$ & $9(6.6 \%)$ & $16(11.8 \%)$ \\
\hline K3 & $105(77.2 \%)$ & $13(9.6 \%)$ & $18(13.2 \%)$ \\
\hline K4 & $114(83.8 \%)$ & $14(10.3 \%)$ & $8(5.9 \%)$ \\
\hline K5 & $122(89.7 \%)$ & $9(6.6 \%)$ & $5(3.7 \%)$ \\
\hline K6 & $112(82.4 \%)$ & $18(13.2 \%)$ & $6(4.4 \%)$ \\
\hline K7 & $121(89 \%)$ & $12(8.8 \%)$ & $3(2.2 \%)$ \\
\hline K8 & $136(100 \%)$ & 0 & 0 \\
\hline K9 & $135(99.3 \%)$ & $1(0.7 \%)$ & 0 \\
\hline K10 & $121(89 \%)$ & $10(7.4 \%)$ & $5(3.7 \%)$ \\
\hline K11 & $135(99.3 \%)$ & $1(0.7 \%)$ & 0 \\
\hline K12 & $106(77.9 \%)$ & $19(14 \%)$ & $11(8.1 \%)$ \\
\hline K13 & $123(90.4 \%)$ & $10(7.4 \%)$ & $3(2.2 \%)$ \\
\hline
\end{tabular}


Table 2

Responses of participants on attitude questionnaire

\begin{tabular}{|c|c|c|c|c|c|}
\hline \multirow[t]{2}{*}{ Questions No } & \multicolumn{5}{|c|}{ Response [n, (\%)] } \\
\hline & Strongly agree & Agree & Neutral & Disagree & Strongly disagree \\
\hline $\mathrm{A} 1$ & $131(96.3 \%)$ & $5(3.7 \%)$ & 0 & 0 & 0 \\
\hline A2 & $128(94.1 \%)$ & $8(5.9 \%)$ & 0 & 0 & 0 \\
\hline A3 & $83(61 \%)$ & $43(31.6 \%)$ & $10(7.4 \%)$ & 0 & 0 \\
\hline A4 & $73(53.7 \%)$ & $62(45.6 \%)$ & 0 & $1(0.7 \%)$ & 0 \\
\hline A5 & $82(60.3 \%)$ & $50(36.8 \%)$ & $3(2.2 \%)$ & $1(0.7 \%)$ & 0 \\
\hline A6 & $112(82.4 \%)$ & $20(14.7 \%)$ & $4(2.9 \%)$ & 0 & 0 \\
\hline A7 & $88(64.7 \%)$ & $43(31.6 \%)$ & $5(3.7 \%)$ & 0 & 0 \\
\hline A8 & 111 (81.6\%) & 25 (18.4\%) & 0 & 0 & 0 \\
\hline
\end{tabular}

\section{Association Of Knowledge With Demographic Characteristics:}

Mean age of the participants with good knowledge was significantly higher than participants with inadequate knowledge $(p=0.047)$. The difference in knowledge among participants was statistically significant $(p=0.001)$ across different academic years with majority $(90.4 \%)$ of interns showing higher level of knowledge followed by fourth year (83.7\%) and third year (58.7\%). However, there was no difference in level of knowledge between males and females as illustrated in Table 3. 
Table 3

Association of Knowledge with Age, Gender and Academic year of the study participants

\begin{tabular}{|c|c|c|c|c|}
\hline & Adequate Knowledge & Inadequate Knowledge & Total & p-value \\
\hline $\begin{array}{l}\text { Age in years [Mean } \\
\text { (SD)] }\end{array}$ & $24.05(1.05)$ & $23.62(0.86)$ & $23.96(1.03)$ & $0.047^{+}$ \\
\hline \multicolumn{5}{|l|}{ Gender [n (\%)] } \\
\hline Male & $37(78.7 \%)$ & $10(21.3 \%)$ & 47 (100\%) & \multirow[t]{2}{*}{$0.992^{*}$} \\
\hline Female & $70(78.7 \%)$ & $19(21.3 \%)$ & $89(100 \%)$ & \\
\hline \multicolumn{5}{|l|}{ Academic Year [n (\%)] } \\
\hline Third year & $24(58.5 \%)$ & $17(41.5 \%)$ & $41(100 \%)$ & \multirow[t]{3}{*}{$0.001^{*}$} \\
\hline Fourth year & $36(83.7 \%)$ & $7(16.3 \%)$ & $43(100 \%)$ & \\
\hline Interns & $47(90.4 \%)$ & $5(9.6 \%)$ & $52(100 \%)$ & \\
\hline \multicolumn{3}{|c|}{ Bold signifies statistical significance at $p<0.05$} & & \\
\hline
\end{tabular}

\section{Association Of Attitude With Demographic Characteristics:}

The age and gender difference among participants with positive and negative attitude was not statistically significant. The difference in attitude among participants was statistically significant $(p=$ 0.011 ) across different academic years with most (90.4\%) of the fourth-year participants showing positive attitude followed by third year (68.3\%) and interns (65.4\%) as displayed in Table 4. 
Table 4

Association of Attitude with Age, Gender and Academic year of the study participants

\begin{tabular}{|c|c|c|c|c|}
\hline & Positive Attitude & Negative Attitude & Total & p-value \\
\hline Age in years [Mean (SD)] & $23.94(0.99)$ & $24(1.11)$ & $23.96(1.03)$ & $0.769^{+}$ \\
\hline \multicolumn{5}{|l|}{ Gender [n (\%)] } \\
\hline Male & $38(80.9 \%)$ & $9(19.1 \%)$ & 47 (100\%) & \multirow[t]{2}{*}{$0.202^{*}$} \\
\hline Female & $63(70.8 \%)$ & $26(29.2 \%)$ & $89(100 \%)$ & \\
\hline \multicolumn{5}{|l|}{ Academic Year [n (\%)] } \\
\hline Third year & $28(68.3 \%)$ & $13(31.7 \%)$ & $41(100 \%)$ & \multirow[t]{3}{*}{$0.011^{*}$} \\
\hline Fourth year & $39(90.7 \%)$ & $4(9.3 \%)$ & $43(100 \%)$ & \\
\hline Interns & $34(65.4 \%)$ & $18(34.6 \%)$ & $52(100 \%)$ & \\
\hline \multicolumn{5}{|c|}{ Bold signifies statistical significance at $p<0.05$} \\
\hline
\end{tabular}

\section{Discussion:}

Assessment of knowledge and attitude regarding infection control is crucial in creating a safer workplace for dental health care providers as well as patients visiting them. This is challenging for academic institutes which is responsible for the grooming of naïve undergraduates into knowledgeable and skilled professionals. Such challenge can be accomplished by consistent inculcation of good knowledge and positive attitude in them with consistent supervision. Various studies have been conducted to assess knowledge, attitude, and practice of infection control policies amongst health care workers in Nepal. However, only few have been recorded among undergraduate dental students which entailed the conduction of the present study.

In the present study, majority of undergraduate dental students in BPKIHS $(78.7 \%)$, had adequate knowledge regarding infection control which is almost like the findings of the study conducted by Embrahimpour et. al and Halboub et al. among undergraduate dental students which showed satisfactory level of knowledge. 1,11 However, there are studies which report inadequate knowledge regarding infection control among undergraduate dental students. ${ }^{4,6}$ The reason for adequate knowledge in our study is the incorporation of infection control training in the curriculum which is routinely conducted both via theory and practical sessions.

Regarding the association of level of knowledge with respect to gender, age, and academic years, there was no significant difference in level of knowledge between males and females though it was higher among the participants with higher mean age and among students of higher academic level. This is in 
accordance with the results of the study conducted at Kantipur Dental College and Hospital, Nepal among undergraduate dental students and interns. ${ }^{4}$ This significant difference is highly plausible in the sense that with increasing age and increasing level of education, knowledge is ought to upgrade. It is notable that, regarding Hepatitis B Virus (HBV)-vaccination status, $89 \%$ were vaccinated against HBV while $7.4 \%$ did not remember their status and $3.7 \%$ reported to be unvaccinated. This finding agrees with $86.50 \%$ vaccinated and $13.50 \%$ unvaccinated status of the students of BPKIHS itself which was reported in a cross-sectional study done by Bhattarai et al. This study included medical, dental as well as nursing students and particularly for dental students, the vaccinated status was $80.2 \%$, which was slightly lesser compared to our study result. ${ }^{12}$ Another cross-sectional study done in Nepal including medical and dental students reported that $73.5 \%$ were vaccinated while $4.5 \%$ had no idea about their vaccination status. ${ }^{13}$ Such increase in percentage of vaccinated students in our study indicates increased awareness among the students with due course of time in Nepal which is a positive finding. On the contrary, much higher rate of vaccinated status has been reported by other studies in UAE (95.8\%), Brazil (90.8\%), and Canada $(100 \%) .{ }^{14-16}$

A couple of striking findings were noted despite good knowledge among majority of the students. Few students were unaware regarding the protocol of changing mask between patients. This could be attributed to the limited supply of such requirements in the institute because of which good clinical practice is being compromised. In addition, few students were found to lack the knowledge regarding post-exposure prophylaxis regimen when an unvaccinated dentist encounters a needle prick injury while treating Hepatitis B surface Antigen positive (HBsAg) patient. It is a serious concern though an occasionally encountered incidence during clinical practice, which calls for conduction of additional lectures and demonstrations to improve their knowledge.

In response to attitude questionnaire, majority of participants (74.3\%) showed 'positive' attitude regarding infection control. This finding again is in congruence with the study done by Alharbi et al. ${ }^{9}$ Similarly, there are various other studies which report positive attitude among the dental students. ${ }^{4,17}$ But there are studies reporting negative attitude as well. ${ }^{6,18}$ Regarding the attitude of different academic year students, it was found that majority of foutth year students showed the most positive attitude. This statistically significant difference may be attributed to the fact that attitude is a subjective domain and hence a result of discrepancy in an individual's beliefs, notions, and behavior. However, there was no difference in attitude noted among different age group and gender.

In the present study, it was appreciable to note that $100 \%$ of the students showed positive attitude regarding the need of all dental practitioners to get vaccinated against HBV, importance of enquiring and recording the medical history of the patients before starting any intra-oral procedures, and the necessity of disposal of used needles and sharp objects into designated sharps container. Such attitude is the reflection of good knowledge reported in the present study which in turn will contribute in strict adherence to infection control guidelines among the naive dental students. 
Still, $0.7 \%$ of the participants disagreed to the statement regarding: effectiveness of wearing two pairs of gloves during any intra-oral surgical procedures to prevent disease transmission and offering face mask to coughing person as they enter the dental setting. However, wearing of double gloves can be incorporated into practice as it has been considered based upon several studies that, double gloving provide protection from occupational blood contact maintaining optimum manual dexterity as well as tactile sensitivity. In addition, the practice of offering mask to coughing persons in the vicinity of clinical set-up has also been recommended by $\mathrm{CDC}{ }^{3}$ Furthermore, few students revealed uncertainty to the CDC guidelines like washing hands before wearing gloves and instructing patients to use pre-procedural mouth rinse before commencement of any treatment procedure. This is of serious issue, which could be implemented in their practice if not supervised strictly. Despite the paucity of existing data which recommend preprocedural mouth rinse to prevent clinical infection among patients or DHCPs, it is advisable to use such rinse prior to aerosol generating procedures (AGPs) because, there are studies that have demonstrated reduction in the level of microorganisms with its use. ${ }^{19,20}$ In relation to washing of hands before wearing gloves, it has been recommended with an explanation that, the integrity of gloves may be compromised via presence of small, unnoticeable defects or even can be torn during use which can contaminate hands during glove removal. Hence, hands should be washed thoroughly before wearing gloves. ${ }^{3}$ Also, there were students though very few, who showed uncertainty as per CDC recommendation according to which responsibilities for disinfection and sterilization of dental instruments and other equipment should be assigned to a trained staff. ${ }^{3}$ Such attitude if not improvised will subsequently produce incompetent professionals who might jeopardize the health system in toto.

Study limitations: One of the major domains of education i.e., practice was not incorporated in the questionnaire because clinical assessment was not feasible as the students were only virtually accessible due to COVID-19 pandemic. Hence, with a view that subjective response would not reflect the true practice of the students, only knowledge and attitude were taken into consideration. Also, the present study did not include dental students from other parts of Nepal, hence making the sample size relatively small. Despite the limitation, the data obtained from the study will help derive information pertaining to existing lacunae regarding knowledge and attitude towards infection control among the undergraduate students. In addition, the results of this study will add to the existing literature and in turn impel conduction of similar studies amongst other group of staffs/ health care personnel in this institute. The result is expected to contribute in strengthening a cautious treatment strategy in the institute in future.

\section{Conclusion:}

The present study reports adequate knowledge and positive attitude regarding infection control among undergraduate dental students in BPKIHS. However, there were minimal number of students showing negative attitude as well, which could be reflected in their practice. This calls for strict supervision during their clinical practice to achieve maximum adherence to infection control protocols and hence create a safer working environment for the dental health care providers as well as patients visiting the set-up. Last but not the least, further studies are encouraged to conduct such assessments among students from 
different institutes all over the country which would provide an insight regarding status of the dental health service of the country.

\section{List Of Abbreviations}

BPKIHS

B. P. Koirala Instititue of Health Sciences

$\mathrm{CDC}$

Centers for disease control and prevention

$\mathrm{Cl}$

Confidence interval

CODS

College of Dental Surgery

COVID-19

Corona virus disease-19

DHPs

Dental health care providers

HCWs

Health care workers

SD

Standard deviation

SPSS

Statistical package for social sciences

\section{Declarations}

\section{Ethics approval and consent to participate:}

Ethical approval was obtained from the Institutional Review Committee, B. P. Koirala Institute of Health Sciences, Dharan, Nepal (Ref. No. 438/077/078-IRC; Code no.: IRC/2042/020) before conducting the study. Participants had to answer a yes-no question in the google form to confirm their willingness to participate voluntarily. All the necessary measures to safeguard participants' anonymity and confidentiality of information were respected.

\section{Consent for publication:}

Not applicable.

\section{Availability of data and materials:}

The datasets supporting the findings of this article are available from the corresponding author. 


\section{Competing interests:}

The authors declare that they have no competing interests.

\section{Funding:}

No funding.

\section{Author's contribution:}

Affiliations:

1. Department of periodontology and Oral Implantology, College of Dental Surgery, B.P Koirala Institute of Health \& Sciences, Dharan, Nepal. Pujan Acharya.

2. Department of microbiology, B.P Koirala Institute of Health \& Sciences, Dharan, Nepal. Ratna Baral.

3. Department: Periodontology \& Oral Implantology, College of Dental Surgery, B. P. Koirala Institute of Health Sciences, Dharan, Nepal. Dr. Sajeev Shrestha.

4. School of Public Health and Community Medicine, B.P Koirala Institute of Health \& Sciences, Dharan, Nepal. Dharanidhar Baral.

\section{Contributions:}

PA: Study conceptualization, questionnaire development, data collection and manuscript preparation. RB: Modifications in research proposal and critical analysis of the final manuscript. SS: Valuable suggestion in the preparation of questionnaire and supervision of the research process. DDB: Statistical analysis and final revision of the manuscript. All authors have read and approved the final manuscript.

\section{Corresponding author:}

Correspondence to Pujan Acharya.

\section{Acknowledgement:}

We would like to acknowledge Prof. Dr. Shivalal Sharma, Dr. Ujwal Gautam and all the undergraduate dental students and interns of college of dental surgery, BPKIHS who participated in the study.

\section{References}

1. Embrahimpour A, Pakraven AH, Nezhad MY, Alipour N, Saravi ME, Rahbar F, SanieKhatam Z. Knowledge and performance of dental students with regard to infection control guidelines in Dental School of Mazandaran University of Medical Sciences in 2015. ljmrhs. 2016;5 (8):298-304.

2. Taiwo J, Aderinokun G. Assessing cross infection prevention measures at the Dental Clinic, University College Hospital, Ibadan. Afr J Med Med Sci. 2002;31(3):213-217. 
3. Kohn WG, Collins AS, Cleveland JL, Harte JA, Eklund KJ, Malvitz DM. Guidelines for infection control in dental health care settings-2003. MMWR Recomm. Rep. 52. RR-17 2003: 1-61.

4. Ghimire B, Chandra S. Awareness of infection control among dental students and interns. JNMA J Nepal Med Assoc.2018;56(210):598-601.

5. Ibrahim NK, Alwafi HA, Sangoof SO,Turkastani AK, Alattas BM. Cross infection and infection control in dentistry: Knowledge, attitude and practice of patients attended dental clinics in King Abdulaziz University Hospital, Jeddah, Saudi Arabia. J Infect Public Health.2017;10(4):438-445.

6. Moradi Khanghahi B., Jamali Z., Pournaghi Azar F., Naghavi Behzad M., Azami-Aghdash S. Knowledge, attitude, practice, and status of infection control among Iranian dentists and dental students: a systematic review. J Dent Res Dent Clin Dent Prospects.2013;7(2):55-60.

7. Girotra C, Acharya S, Shetty O, Savla S, Punjani M, Shah T. Assessment of KAP towards infection control among dental UG students: A cross-sectional survey. J Indian Assoc Public Health Dent.2021;19:65-70.

8. Shrestha S., Thakur S., Dulal N. Knowledge and Practice of Infection Control in Impression Making among the Dental Health Care Professionals. Journal of College of Medical Sciences-Nepal. 2019; 15(4), 244-248.

9. Alharbi G., Shono N., Alballaa L. Aloufi A. Knowledge, attitude and compliance of infection control guidelines among dental faculty members and students in KSU. BMC Oral Health. 2019; 19 (1):7.

10. Seid, M.A., Hussen, M.S. Knowledge and attitude towards antimicrobial resistance among final year undergraduate paramedical students at University of Gondar, Ethiopia. BMC Infect Dis. 2018; 18 (1): 312.

11. Halboub ES, Al-Maweri SA, Al-Jamaei AA, Tarakji B, Al-Soneidar WA. Knowledge, attitudes, and practice of infection control among dental students at Sana'a University, Yemen. J Int Oral Health. 2015;7(5): 15-19.

12. Bhattarai S., KC S., Pradhan, P.M. Lama S., Rijal S. Hepatitis B vaccination status and Needle-stick and Sharps-related Injuries among medical school students in Nepal: a cross-sectional study. BMC Res Notes 2014; 7(1): 774.

13. Shah.D.K., Jha.R.K., Ansari S, Sah P, Dhungana G.P., Basnet S. Knowledge and awareness regarding hepatitis B among preclinical medical and dental students of Chitwan Medical College Nepal: a questionnaire-based study. Int J Med Sci public Health.2016; 5(11):2316-2321.

14. Rahman B., Abraham S.B., Alsalami A.M., Alkhaja F.E., Najem S.I. Attitudes and practices of infection control among senior dental students at college of dentistry, university of Sharjah in the United Arab Emirates. Eur J Dent. 2013; 7(Suppl 1): S15-S19.

15. De Souza RA, Namen FM, Galan J Jr, Vieira C, Sedano HO. Infection control measures among senior dental students in Rio de Janeiro State, Brazil. J Public Health Dent 2006; 66 (4):282-284.

16. McCarthy GM, Britton JE. A Survey of Final year Dental, Medical and Nursing Students: Occupational Injuries and Infection Control. J Can Dent Assoc. 2000;66(10):561. 
17. N.A. AL-Essa, M.A. AlMutairi. To what extent do dental students comply with infection control practices? The Saudi Journal for Dental Research. 2017; 8:67-72.

18. Li R, Dong W, He W, Liu Y. Chinese dental students' knowledge and attitudes toward HIV/AIDS. J Dent Sci. 2016;11(1):72-78.

19. Fine $\mathrm{DH}$, Mendieta $\mathrm{C}$, Barnett $\mathrm{ML}$, et al. Efficacy of preprocedural rinsing with an antiseptic in reducing viable bacteria in dental aerosols. J Periodontol. 1992;63(10):821-4.

20. Marui VC, Souto MLS, Rovai ES, Romito GA, Chambrone L, Pannuti CM. Efficacy of preprocedural mouthrinses in the reduction of microorganisms in aerosol: A systematic review. J Am Dent. 2019;150(12):1015-1026.e1. 